\title{
GENDER AND SUCCESS IN THE AMERICAN DANCE WORLD
}

\author{
By: JAN VAN DYKE
}

Van Dyke, J. 1996: Gender and Success in the American Dance World, Women's Studies International Forum, volume 19/number 5.

Made available courtesy of Elsevier (Pergamon):

http://www.sciencedirect.com/science/journal/02775395/

\section{***Note: Figures may be missing from this format of the document}

\begin{abstract}
Abrtact:
This article will explore the relationship of gender to funding for dance in the United States. Historically a female field in this country, since the 1960s, dance in America has turned to men for its leadership. At about the same time, in 1965, the National Endowment for the Arts was founded - the first government agency organized to "encourage and support American art and artists." Until that year, the arts in the United States had relied almost exclusively on priviate patronage for support. Over the years, the Endowment has taken an authoritative role in arts giving, seeking to influence funding from corporations and individual sources and, in effect, giving artists an imprimatur when they are selected for NEA awards. Research will focus on the U.S. government funding process, describing the hierarchy of federal, state, and local agencies, and giving special attention to NEA policies because of their impact on all other sources of funding. For purposes of clarity, the article will concentrate on grants given to individual artists; the make-up of selection panels will be examined along with the success rate of both men and women applicants. In addition, current gender ratios within various areas of American dance will be described in order to assess the relationship of gender to artistic, economic, and administrative leadership within the profession.
\end{abstract}

\section{Article:}

Dance occupies a strange, not always comfortable position in American culture, marginal and yet compelling. It is a field largely populated by women, which, at least in part, accounts for its marginalization. As a form, it intrigues people but the art itself is not widely followed or understood. In spite of that — or perhaps because of it - young women from a broad socioeconomic spectrum are drawn to train and dream of one day "making it." Most begin the training as children, brought to classes by their parents. Dance classes for little girls are considered part of growing up in many American families.

This article is primarily concerned with exploring the effects of gender within the American dance world, using the distribution of funding, employment, and awards to gauge opportunity and satisfaction. Special attention will be paid to funding policies and procedures because it is the grants process that fuels the engine of the field these days. Access to funding determines who will be visible, whose work will be seen, whose dancers will be paid, and who will attract more funding. Funding in America is the key to status and prestige in the professional world. Even for dance artists in higher education, there is pressure from within the university to build one's reputation and establish proof of excellence by finding outside support. Before beginning the 
discussion about gender, it will be helpful to understand a bit about the American dance world and the role funding plays.

\section{A BRIEF HISTORY OF GOVERNMENT FUNDING IN THE UNITED STATES}

As a democracy with strong capitalist values and a reverence for individualism, the United States has had a difficult time embracing the idea of government funding for the arts. Prior to 1965, when the National Endowment for the Arts (NEA) was founded - the first government agency organized to "encourage and support American art and artists" (NEA, 1987, p. vii) — the country relied heavily on volunteerism, private initiative, and patronage for the support of the arts.

Language used by the U.S. Congress to authorize the Endowment clearly sets out the American idea that although now the government has an acknowledged role to play, private support for the arts is still of primary importance: "The encouragement and support of national progress and scholarship in the humanities and the arts, while primarily a matter of private and local initiative, is also an appropriate matter of concern to the Federal Government" (NEA, 1987, p. 222). To this end, most government grants to arts institutions must be matched at least dollar for dollar with funds raised from the private sector. Livingston Biddle, Chairman of the Arts Endowment from 1977 to 1981, describes the Endowment's role as that of a catalyst: By using federal funds to match donations from the private sector, the government is able to point individual and corporate contributions toward the arts in ratios of up to four to one (Biddle, 1984). In this way, NEA grants confer not only money, but a credential, a stamp of approval that carries an advantage in the competition for private funds. Moreover, these grants confer status, both within the dance world and without. Artists see this plainly, as is made clear by the biographies and resumes that list grants received as though they were honors. Within universities too, faculty artists list "outside support" as a credential that is well respected and understood throughout the academic hierarchy.

In 1967, 2 years after its establishment, the NEA began making large "block" grants available to state arts councils. Before this time, only 22 state governments - fewer than half — had appropriated any funds to a state-level arts agency, and those funds that had been assigned were meager. Combined appropriations for the 21 states other than New York totaled $\$ 505,000$, at that time barely enough to pay the salary of a single, full-time staff member in each state. Because of the sudden availability of federal funds for regional distribution, however, by 1972 all 50 states and the District of Columbia, Puerto Rico, and three overseas juridictions had arts councils receiving both NEA and state appropriations (Netter, 1978).

Today, public funds are generally available to artists at three levels: (a) While all grants confer status, the most competitive and prestigious are those from the federal government: grants from the NEA; (b) the states vary greatly in their support of the arts, but as noted, all now make some funds available. A percentage of funds given out at the state level comes from the NEA; (c) cities and counties often have money to be dispersed on a "grassroots" level. A portion of these funds, too, frequently comes from state and federal agencies for local distribution.

The Endowment states its mission as two- pronged: to foster excellence and diversity in the arts and to make the arts more broadly available. From the beginning, financial support has been available from the NEA for touring. With grant money and organizational support at hand for 
presenters nationwide, dance companies can now show their work throughout the country. The agency is fulfilling its goal of making dance more widely available. A national market for dance has been developed, effectively expanding the field beyond New York City, and increasing work opportunities for both companies and dancers (Van Dyke, 1992).

For all these reasons, public funding policy is seen as central to careers in the American dance world. Access to funding is critical for both visibility and attracting future funds. Since professional awards and opportunities tend to go to those whose work is known, grants have taken on major significance, and inequities in support are reflected in almost all other measures of artistic success.

\section{GENDER AND PROFESSIONAL DANCE IN AMERICA}

In the United States, the majority of dance artists are women. Girls outnumber boys, women outnumber men in virtually every dance school and studio, whether modern, ballet, or jazz. For example, in the 1989 session of the American Dance Festival in North Carolina, there were only 32 males enrolled out of over 200 students in the Six Week School; that is less than 16\%. In 1993, 79\% of the students were female: there were 219 women and 58 men (Van Dyke, 1993). In 1994, again, out of 272 full-time students in the Six Week School, $21 \%$ were men.

These numbers only tell one side of the story, however. In 1961, critic John Martin, writing in the New York Times, noted a new trend: That year, for the first time, the bulk of the New York season was produced by male choreographers (Hanna, 1987). Since then, despite an overwhelming majority of women in the dance population, we have seen the emergence of male leadership in the field, as reflected in awards, recognition, and employment.

As cited by Hanna (1987), an early study, made in 1976 by Wendy Perron and Stephanie Woodward, illustrates the situation. Perron and Woodward gathered data from the 1900 students and company members of six New York City modem dance and ballet companies with affiliated schools, and found that $32 \%$ of the students were male. Although that figure is high in comparison with the typical community- based studio or university dance program, even here male students were found to succeed out of proportion to their numbers: Although $32 \%$ of the students were male, scholarship students were $38 \%$ male and $45 \%$ of dance company members were men (Hanna, 1987.) On the whole, because there are fewer male dance students, and most companies would like an approximately equal number of men and women, it seems clear that young women do not have the same success rate as their male peers.

Statistics on opportunity and recognition are incomplete, but they do seem consistent with the notion that men now lead the professional dance field in the United States. Not only do they receive jobs as performers out of proportion to their representation as dance students, they also achieve acclaim more readily. This is especially clear when one examines national honors and awards given to dance artists:

1. From 1952 to 1992, the Capezio Dance Award was a cash prize given annually to a dancer, choreographer, critic, teacher, producer, or administrator for significant contribution to dance in the United States. After 1992, it was changed to include companies and institutions as well. Over the 40 years between 1952 and 1992, the award went to 34 men and 17 women. 
2. The Kennedy Center of the Performing Arts in Washington DC holds an annual celebration honoring American performing artists for lifetime achievement. Of the 85 men and women honored between 1978 and 1993,16 have been dance artists, 11 of them men and five women.

3. According to the 1994 award ceremony program, the Samuel H. Scripps American Dance Festival Award was "established to honor those great choreographers who have dedicated their lives and talent to the creation of our modem dance heritage." Instituted in 1981, this award has, through 1994, been given to nine men and seven women.

4. The Dance Magazine Awards, since their inception in 1954 through 1994, have been divided among 68 men and 54 women.

\section{GENDER AND TEACHING}

Many dance artists depend on guest teaching opportunities to round out their yearly income. More important than a mere job, these positions are seen as occasions to show work, build reputation, pass on points of view, recruit dancers and broaden one's audience. Guest artist jobs are highly sought after and are, in a sense, another kind of professional award.

Dance festivals in the United States draw heavily on performers and choreographers for their faculty, making use of well known names and company affiliations as a means of advertising quality and excitement. Here, men are represented in strength even though, as noted above, student attendance is largely female. For example, the advertising brochure for the 1993 American Dance Festival Six Week School listed 39 professionals on its teaching staff: 25 men and 14 women. In 1994, the ADF program listed 35 faculty names for the Six Week School: 21 men and 14 women. In Boston, the Harvard Summer Dance Center brochure for 1994 advertised a faculty of 10 men and six women. Perry Dance II Studios in New York described its Summer '94 Dance Program as a Choreographers/Master Teachers Series with a faculty of six men and one woman and a dance company called Mr. Wiggles. As the exception, the 1994 Colorado Dance Festival had women in good evidence: their brochure gave the names of 29 faculty women and 11 men.

The values apparent in the professional world today seem to be affecting hiring priorities within academia as well. Once clearly the domain of women, now many college dance faculties are striving for gender equity regardless of the numerical dominance of women as dance students. In fact, one reason for increasing the number of men on the faculty is the hope of attracting more male students. At the University of North Carolina at Greensboro, for example, during the 19931994 school year there were 80 undergraduate dance majors, of whom three were male. The fulltime faculty during that period consisted of five women and three men. For the following year, 1994-1995, the faculty ratio changed to five men and four women. This is not atypical of schools across the country. An informal sampling of departmental advertisements in the 1994 program for the American Dance Festival reveals the following gender ratios in departments nationwide (Table 1).

Perhaps the one area where women are still indisputably in charge is in the leadership of these same dance departments. This is borne out by checking the 1994-95 Dance Magazine College Guide (Stern, 1994). Typically, each school's listing in this publication includes the name of a chair, coordinator, director, head, dean, or contact person. A count shows 257 dance programs with female leadership, 63 with a male listing, and 20 where the name does not clearly indicate gender. 
Possible explanations for the overwhelming majority of female dance administrators within the college system must be offered cautiously. Certainly, because departmental student bodies are largely female, more women are academically qualified to fill these jobs. Perhaps, too, because women are in proportionally less demand as performers, they tend to extend their educations in order to sustain an active involvement in the field, and so are more likely than men to have graduate degrees. This is one job for which, historically, one has not had to be visible as an artist to qualify. Moreover, because dance within American universities began as part of women's physical education programs, women have simply been part of the system for a longer time and so form the greater part of the pool of qualified candidates.

Sue Stinson (personal communication, July 6, 1994), Chair of the UNC/Greensboro Department of Dance, offers an additional point of view when she notes that in many of the smaller dance programs, especially where there is no actual department of dance, administrative positions tend to involve a lot of housekeeping duties and little power, keeping the job well within the realm of "women's work." Whatever the reasons, it seems only a matter of time when, as more men join dance faculties, they will become interested and eligible for these administrative positions. It remains to be seen whether more male students will be attracted to the field with the increase in male teachers. Meanwhile, a concern is whether mixed faculties will continue to meet the needs of their large numbers of female students or whether, perhaps, young women will come to regard academic dance programs as just one more place where men are given special consideration.

\section{GENDER AND FUNDING}

Despite periods of intense political disfavor, since its founding in 1965 the National Endowment for the Arts has taken on a leadership role in defining art in America. Through the distribution of its own funds and, more importantly, through its influence on other government funding agencies, private foundations, corporations, and individual donors, the agency has become a major force.

NEA policies have profoundly affected the organization of the American professional dance world, with wide-ranging impact on the lives of dance artists and their work. Since 1965, the profession has been changed from a disorganized group of small operations to a centrally focused, national field of nonprofit, tax-exempt corporations with boards of directors.

In promoting its goals, the NEA has used funding guidelines to reshape the dance world, requiring compliance for eligibility. It has had additional influence through the creation of funding categories, effectively stimulating interest in government goals by making money available to carry them out. For example, by providing funds for professional management and then making evidence of management staff a credential of artistic professionalism and a requirement for certain grants, the NEA has directed dance companies toward a business model. 


\begin{tabular}{lcc}
\multicolumn{2}{c}{$\begin{array}{c}\text { Table 1. A Sample of Gender Ratios for University Dance } \\
\text { Departments in the United States }\end{array}$} \\
\hline University & Women & Men \\
\hline East Carolina University in North Carolina & 3 & 2 \\
CalArts School of Dance in California & 5 & 4 \\
University of Minnesota & 7 & 1 \\
Guest artists & 3 & 4 \\
University of Illinois & 4 & 4 \\
Texas Christian University & 6 & 1 \\
\hline
\end{tabular}

Men have traditionally had more success than women in the area of funding, and have, over the years, been awarded more grant money. Again, Perron and Woodward's early study (Hanna, 1987) speaks to the situation. They surveyed recipients of 316 dance grants given by the National Endowment for the Arts during 1974 and 1975 and by the New York State Council on the Arts during 1971-1974. Data showed that although 55\% of company members were female at that time, $73 \%$ of grant recipients were male. Of grantees receiving $\$ 70,000$ or more, $100 \%$ were male. Although this research is more than 20 years old, it continues to be generally accurate in its portrayal of the field.

The 1985 Annual Report of the National Corporate Fund for Dance lists seven dance companies that received benefits from its 1985 campaign. All were directed by men, including Alvin Ailey, Merce Cunningham, and Paul Taylor. Eleven companies are listed in the 1988 report, and of these, three were directed by women. In 1992, the National Corporate Fund for Dance terminated operations, and reorganized itself as the Fund for Dance, a membership organization that conducts an annual campaign within the business community to help its members raise funds. Of the eight member companies listed in 1993, seven were directed by men (Daniels \& Schwartz, 1994).

Among the most intriguing and prestigious grants in the United States are those offered by the John D. and Catherine T. MacArthur Foundation through the MacArthur Fellows Program — the so-called "genius" grants. Since the program began in 1981, 434 Fellows have been named, including eight dance artists. Individuals cannot apply for these grants; instead they are selected annually by anonymous nominators. No conditions are placed on use of funds, which range from $\$ 160,000$ to $\$ 375,000$ over 5 years. There is no annual quota of Fellows and no predetermined time for naming them. Among the eight choreographers selected thus far, three have been women.

At the federal level, NEA grant-giving showed a bias early on. As the agency began operations in 1965, choreographers were the first individual artists recommended for grants by the National Council on the Arts; however, of the eight grants awarded, six went to men (Netzer \& Parker, 1993). Since then, the agency has made an effort to distribute funds to choreographers more equitably.

Currently, the only NEA Dance Program grants available solely to individuals (as opposed to companies and institutions) are the Choreographer's Fellowships. These are outright grants that do not require matching funds. For the 1995 grant cycle, the Fellowships were awards of either $\$ 20,000$ over 2 years or $\$ 7,000$ over 1 , representing $9-10 \%$ of the funds accorded to dance that year. Suzanne Callahan (personal communication, June 28, 1994), Senior Program Specialist in 
the Dance Program at the Endowment, provided figures for awards during 1994 and 1995 (Table 2).

The inequity is revealed in the "success rate," the percentage of total applicants who are funded. Because over twice as many applicants in 1995 were female, the success rate for men was more than double that for women. There were 137 male applicants and 282 female applicants: a 20\% success rate for men and $8 \%$ success rate for women.

Callahan had no easy explanation for the discrepancy apparent in these figures. She was clear, however, that men are not taken more seriously in the funding process: "No, not by our panel, absolutely not." When, upon reflection, she could not come to a satisfying interpretation of the figures, she offered the fact that twenty out of the 50 grantees were non-White in 1995. "I sense no gender bias at all," she said.

Although the number of total applicants is not published in the Annual Reports, making it impossible to compare success rates in other years, a review reveals that women have sometimes won more federal grant money than men. The Annual Reports show that in 1988, 61 women and 36 men received Fellowships. In 1989, Fellowships for 36 men averaged \$8,180 while those for 50 women averaged $\$ 10,250$.

State and local arts agencies are often more responsive to the field as it exists in their areas, perhaps because they are smaller and closer to their constituencies. This has proved true in the case of North Carolina. In fiscal 1993, North Carolina ranked 29th among the 50 states in per capita spending on the arts: $\$ .71$ was spent on each person in the state. (For perspective: The

\begin{tabular}{lcc}
\multicolumn{3}{c}{ Table 2. Award Figures For 1994 and 1995 Grant Cycles } \\
\hline Grant Cycle & Awards to Men & Awards to Women \\
\hline 1994 & 22 & 27 \\
1995 & 28 & 22 \\
\hline
\end{tabular}

national average that year for state arts agencies was \$.84.) Most of the money available at this level is allocated by the state legislature, an elected body of representatives that controls all state spending. In addition to state tax dollars, about $14.5 \%$ of the North Carolina arts budget is granted by the NEA for distribution on the state level. Individuals were awarded approximately $6.6 \%$ of the North Carolina Dance Section budget in fiscal 1991-1992; that percentage increased to 7.6\% in fiscal 1992-1993 (Peter MacBeth, personal communication, July 5, 1994).

Between 1983 and 1994, North Carolina offered Choreographer's Fellowships every other year, and over that 11-year period, made eight awards. Five of these went to women, $62.5 \%$, while the applicant pool averaged $76.3 \%$ female. At $81 \%$, this is significantly better than the NEA success rate. The state also offers a choreographic project grant, and here, over the 11 years in question, awards have neatly reflected the ratio of applications: For this grant, the applicant pool averaged $87 \%$ female and women won $84 \%$ of the grants.

\section{THE GRANT MAKING PROCESS}


The process by which the NEA Dance Program makes funds available involves the use of peer panels, long considered the most appropriate means of making qualitative decisions within the arts. Grant categories cover such areas as Grants to Dance Presenters, Dance/Film/Video, and General Services to the Field. Separate panels are selected for each category.

The Dance Program director (Sali Ann Kriegsman at the time of this writing) selects a slate for each panel with staff and field consultation. Then, with qualifications listed beside each name, all nominations must go to the NEA Chairman (currently Jane Alexander) for review and approval. Limited somewhat by pragmatic considerations such as who is available when, the program director and staff work to compile slates that will ensure equity among the professional areas of ballet, modem dance, administration, arts patronage, criticism, and dance presentation. In addition, lay individuals who are knowledgable about the arts but not involved with them professionally or otherwise must be included. The list is then balanced against geographical considerations and aesthetic points of view, also taking into account the need for an equitable mix of men and women and minority representation (Van Dyke, 1992).

Sizes of panels vary and percentages from each area of interest differ according to the nature of the panel. For example, on the Choreographer's Fellowships panel, an attempt is made to include more artists. Generally, panelists serve a maximum of 3 years and approximately one-third of each panel rotates off each year. Some panelists serve on more than one panel at a time for the sake of continuity and broad overview, the same reason that most serve for more than 1 year.

Dance Program administrator Jack R. Lemmon, interviewed in 1988, explained that the criteria for selecting panel members has to do with perceived expertise. In terms of dance artists, he said, although it would not be fair to tie panel selection to past funding decisions, it would be inappropriate for the agency to include an artist who has submitted consistently unsuccessful proposals. Artists "whose work isn't strong" by NEA standards have no place on its panels evaluating other artists. The measure of qualification is excellence, as seen through the eyes of program director, staff, and past panels (Van Dyke, 1992).

The NEA Annual Reports list panels for all grants. As with most Dance Program panels, a check of the gender breakdown for Choreographer's Fellowship panels in the five most recent Reports available reveals a fairly consistent balance. However, it is instructive to note that when there is an imbalance, it has been toward a male majority (Table 3).

The genders are not so fairly represented at the top of the agency hierarchy. The National Council on the Arts, the board charged by law with advising the Chairman of the National Endowment for the Arts and reviewing and making final recommendations on grant applications, has historically been less evenly divided (Table 4). The Council is composed of the

\begin{tabular}{|c|c|c|}
\hline Year & Men & Women \\
\hline 1987 & 5 & 3 \\
\hline 1988 & 5 & 5 \\
\hline 1989 & 6 & 6 \\
\hline 1990 & 6 & 6 \\
\hline 1991 & 7 & 5 \\
\hline
\end{tabular}




\begin{tabular}{|c|c|c|}
\hline Year & Men & Women \\
\hline 1987 & 23 & 10 \\
\hline 1988 & 19 & 7 \\
\hline 1989 & 17 & 9 \\
\hline 1990 & 15 & 9 \\
\hline 1991 & 18 & 11 \\
\hline
\end{tabular}

Chairman of the NEA, who serves as Council Chair, and "26 presidentially appointed citizens who are recognized for their knowledge of the arts, or for their expertise or profound interest in the arts" (NEA, 1987, p. vii). Through their actions, the tone for the government grants making process is set.

\section{THE MOST RECENT RESEARCH ON AMERICAN CHOREOGRAPHERS}

In 1993, the Endowment published Dancemakers, a study on choreographers working in the United States - the first of its kind. The authors drew data from a questionnaire sent out in 1989 to 1,444 choreographers in four cities: New York, Chicago, San Francisco, and Washington DC. Because the response rate was low in 1991 (35.7\%), a briefer telephone survey was made to enable a comparison of the characteristics of choreographers who had responded to the mail survey with those who had not. More than $80 \%$ of choreographers contacted by telephone responded (Netzer \& Parker, 1993).

The report is beautifully packaged as a small book, complete with photographs of dancers and choreographers; these photos tell a story of their own. Although $73 \%$ of those who participated in the study were female, only two pictures show female dance artists at work. Of the others, five show men only, and two depict women and men together.

Taken as a whole, the report provides a bleak picture of the lives of choreographers in this country, expecially in terms of economic status as compared to the high levels of education many receive. Findings reveal that choreographers have one of the highest college completion rates of all professions for which there is no formal certification or licensing requirement: Among those in the study, $77 \%$ were college graduates andlor had advanced professional degrees, compared to $21 \%$ of the U.S. population over age 25 (Netzer \& Parker, 1993). In spite of this, the median total income for all choreographers in $1989(\$ 18,500)$ was only two-thirds of the median earnings for all American women professionals $(\$ 27,900)$. When income from choreography alone is considered, on average, respondents earned only $\$ 6,000$ including grants.

The gender differential here was found to be approximately $\$ 4,500$ or $48 \%$ : For men, average income from choreography including grants was twice that for women (Table 5; Netzer \& Parker, 1993). Survey data show that grants to men average about $50 \%$ more than grants to women (Netzer \& Parker, 1993). The study's authors were not able to provide reasons for the differences drawn here:

There is no obvious explanation for this; the female respondents were more highly educated than the males and about as experienced. Statistical analysis shows that, when all differences in the characteristics of the surveyed men and women were considered, being a woman resulted in $\$ 3,804$ less income from choreography. (Netzer \& Parker, 1993, p. 59) 
Discrepancies such as these have not yet become an issue in the American dance world. In terms of choreographers' views, the authors write that although $40-50 \%$ of respondents sometimes felt discriminated against because of the style of their work, and $18 \%$ perceived a racial bias, only $13 \%$ reported feeling excluded on the basis of gender. Also, the report continues, "men and women did not differ much in their perceptions of gender discrimination in the funding process, despite the study findings of substantial differences in grant amounts and incomes" (Netzer \& Parker, 1993, p. 68). Apparently, the actual figures, which speak fairly clearly of inequities in favor of men, are not yet widely known to either gender.

\begin{tabular}{lcc}
\multicolumn{3}{c}{ Table 5. Breakdown of Choreographers' Incomes } \\
\hline Income & Men & Women \\
\hline $\begin{array}{l}\text { Choreography income } \\
\text { including grants }\end{array}$ & $\$ 9,328$ & $\$ 4,784$ \\
$\begin{array}{l}\text { Choreography income } \\
\text { excluding grants }\end{array}$ & $\$ 7,233$ & $\$ 3,339$ \\
\hline
\end{tabular}

\section{CONCLUSIONS}

It is generally accepted that art reflects the culture within which the artist works, and that the surrounding society has a profound effect in terms of economics and ideas (Adair, 1992). Because the construct of gender in America places women in a less powerful position than men, both the careers of female artists and the perceived importance of their work are bound to be adversely affected.

Yet, the myth that dance is a women's field lives on. In an article entitled "Modern Dance and the Powerful Presence of Women," Stephanie Reinhart (1994), codirector of the American Dance Festival, was recently interviewed. "Modern dance has been an area in which women have clearly been in charge," she said,

in which they've really made their mark - as artists, choreographers, dancers and administrators. The field has been wide open to women and allowed women extraordinary freedom. For example, Charles Reinhart was the first male director of the ADF. All the others had been women. (Reinhart, 1994, p. 5)

Despite Reinhart's perceptions, her own organization stands in contradiction. In both 1993 and 1994, the American Dance Festival has had a faculty ratio of more than 3:2, men to women, and a student body that is $80 \%$ female.

This reflects an ongoing cycle that will be self-perpetuating until a conscious and sustained effort can be made to break it. The bias has one source in the field itself. For years, choreographers and teachers, struggling against the marginalization of the art, have encouraged boys and men to enter the profession, hoping to legitimize the field by equalizing the numbers. Males have been offered opportunities and attention, which, in many respects, has given them a privileged position. This is now evident statistically: The men who were invited in have gained employment and notoriety out of proportion to their numbers. 
The figures cited throughout this article teach a subtle lesson to young dance students. Even in a field pioneered and populated by women, female dance artists today have a disproportionately difficult time achieving recognition and employment. There is less opportunity in the studio and onstage for women than for men, in addition to less visibility in the media, despite the numbers. This daily reinforcing of traditional gender roles translates into a loss of confidence and lowered expectations for young female dancers. "'What girls see is a very powerful force in motivating and shaping their behavior,' says Ruby Takanishi, executive director of the Carnegie Council on Adolescent Development" (Golden, 1994, p. 53). What they are seeing today in dance will not help them easily believe that this is an equal opportunity profession.

In addition, the field's position in the culture is problematic. Within the mainstream of American society, dance is considered an exotic form about which little is - and can be - known. Cynthia Novack (1990) writes:

This view is reinforced by the almost complete absence of reference to dance within the literature on American culture and art. Treatments of postmodernism in "all the arts" generally include literature, visual art, film, architecture, pop music, and new music, but not dance or theater. (p. 229)

Perhaps for this reason, with the exception of feminist dance writers and writers who address gendered issues of the body, feminism has not seriously considered dance. Research that examines social issues and contexts is needed both to further explore these concerns and to bring them to more general awareness. The strong numerical presence of women in the field clearly has not been sufficient to ensure that women maintain even equal representation in professional leadership. Thought and work now must be applied to policies and practices that influence opportunity. For women's perspectives to be positively established and visible, women must have access to positions of power and decision making as choreographers, administrators, presenters, and professors. This is, perhaps, most important for the long-term. Strong and capable women in leadership roles today speak to women's possibilities and provide models for the young female students who fill the studios and aspire to work in the field tomorrow.

\section{REFERENCES}

Adair, Christy. (1992). Women and dance. New York: New York University Press. Biddle, Livingston. (1984). Our government's support for the arts: Nourishment or drought? In Patricia A. McFate (Ed.), The annals of the American academy of political and social science: Paying for culture, 471, 89-101.

Daniels, Peggy K., \& Schwartz, Carol A. (1994). Encyclopedia of associations (28th ed.).

Detroit, MI: Gale Research Inc.

Golden, Kristen. (1994, May/June). What do girls see? Ms., pp. 52-61.

Hanna, Judith Lynne. (1987). Patterns of dominance. The Drama Review, 14, 24-47.

National Endownment for the Arts. (1987-1991). Annual report. Washington, DC: Author.

Netzer, Dick. (1978). The subsized muse. Cambridge: Cambridge University Press.

Netzer, Dick, \& Parker, Ellen. (1993). Dancemakers. Washington, DC: National Endowment for the Arts.

Novack, Cynthia J. (1990). Sharing the dance. Madison, WI: University of Wisconsin Press. Reinhart, Stephanie. (1994, July). Modern dance and the powerful presence of women. Carolina Woman, pp. 5-7. Stern, Robert D. (1994). 1994-95 Dance Magazine college guide. New York: Author. 
Van Dyke, Jan. (1992). Modern dance in a postmodern world. Reston, VA: American Alliance for Health, Physical Education, Recreation and Dance.

Van Dyke, Jan. (1993, Fall). 2:1 hiring ratio raises gender issue at ADF. Dance Voice, p. 2. 